University of South Carolina

Scholar Commons

2009

\title{
A Miniature Spiral Diversity Antenna System with High Overall Gain Coverage and Low SAR
}

\author{
Abu T.M. Sayem \\ Motorola, Inc., abu.sayem@motorola.com \\ Sadia Khan \\ University of South Carolina - Columbia \\ Mohammod Ali \\ University of South Carolina - Columbia, alimo@engr.sc.edu
}

Follow this and additional works at: https://scholarcommons.sc.edu/elct_facpub

Part of the Electrical and Computer Engineering Commons

\footnotetext{
Publication Info

Published in IEEE Antennas and Wireless Propagation Letters, Volume 8, 2009, pages 49-52.

http://ieeexplore.ieee.org/xpl/Recentlssue.jsp?reload=true\&punumber=7727

(C) 2005 by IEEE
}

This Article is brought to you by the Electrical Engineering, Department of at Scholar Commons. It has been accepted for inclusion in Faculty Publications by an authorized administrator of Scholar Commons. For more information, please contact digres@mailbox.sc.edu. 


\title{
A Miniature Spiral Diversity Antenna System With High Overall Gain Coverage and Low SAR
}

\author{
Abu T. M. Sayem, Sadia Khan, and Mohammod Ali, Senior Member, IEEE
}

\begin{abstract}
A miniature spiral diversity antenna system operating at $1.85 \mathrm{GHz}$ is proposed. Two $10 \mathrm{~mm} \times 6.25 \mathrm{~mm}$ antennas were placed at two corners of a printed circuit board at a height of $7 \mathbf{~ m m}$ from the ground plane. Each antenna achieves nearly $7 \%$ bandwidth within $6 \mathrm{~dB}$ return loss. The mutual coupling between the two antennas is less than $10 \mathrm{~dB}$. The proposed diversity antenna scheme exhibits high overall gain performance in all three principal planes compared to a single antenna solution. Computed specific absorption rate (SAR) data against a specific anthropomorphic mannequin (SAM) phantom and a hand model show that the diversity antenna system induces low SAR compared to a single antenna.
\end{abstract}

Index Terms-Antennas, diversity, planar inverted-F antenna (PIFA), specific absorption rate (SAR).

\section{INTRODUCTION}

D IVERSITY antennas have attracted major interests among researchers and engineers due to their tremendous potentials to improve the capacity and quality [1] of a wireless channel. Until very recently the application of diversity antennas has mostly been limited to in the base stations [2]. Although authors have earlier proposed diversity concepts for mobile handheld wireless terminals [3], [4], the challenges of designing and implementing multiple antennas within small portable devices have been very difficult to address. Nevertheless, progress in the realm of miniaturized antenna design has made it possible to look into diversity or smart antenna design at least at the higher frequencies, $1.8 \mathrm{GHz}$ or higher [5], [6]. The specific absorption rate (SAR) characteristics of a smart antenna system were studied in [5], where two identical planar inverted-F antennas (PIFAs) were investigated. In this letter, we present the study of a miniature diversity antenna system which operates at $1.85 \mathrm{GHz}$ and provides excellent gain coverage compared to a single antenna system. We study and demonstrate that the proposed diversity antenna scheme induces lower SAR than a single antenna in a specific anthropomorphic mannequin (SAM) phantom [7].

Manuscript received November 06, 2008. First published December 16, 2008; current version published April 17, 2009. This work was supported in part by the National Science Foundation Career Award ECCS: 0237783.

A. T. M. Sayem was with the University of South Carolina, Columbia, SC 29208 USA. He is now with Motorola, Inc., Libertyville, IL 60048 USA (e-mail: abu.sayem@motorola.com).

S. Khan and M. Ali are with the Department of Electrical Engineering, University of South Carolina, Columbia, SC 29208 USA (e-mail: alimo@engr.sc. edu).

Color versions of one or more of the figures in this letter are available online at http://ieeexplore.ieee.org.

Digital Object Identifier 10.1109/LAWP.2008.2010961

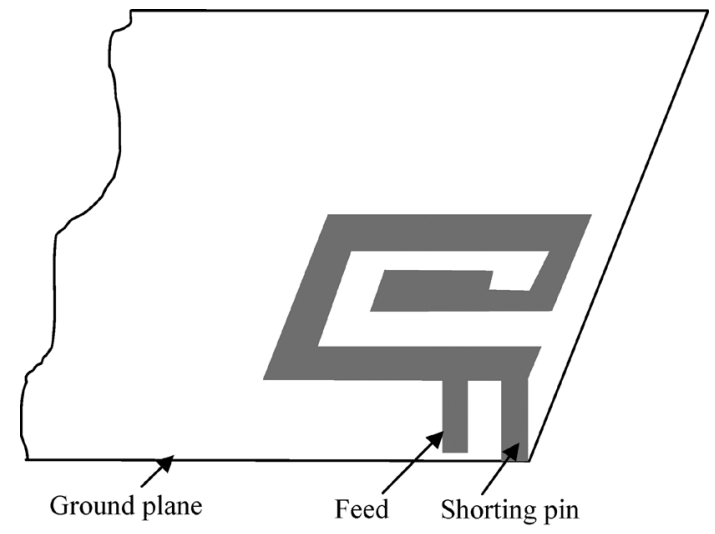

(a)

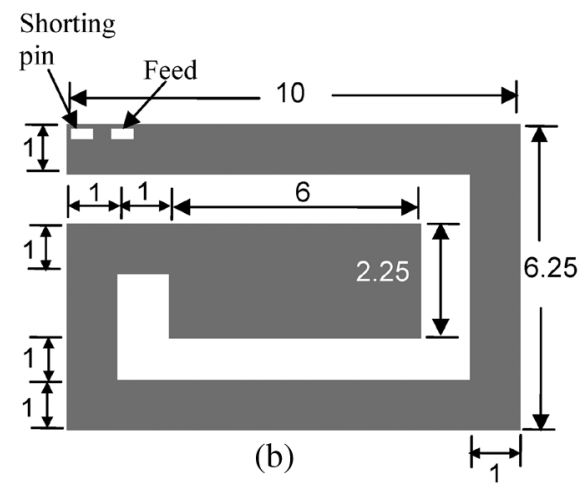

Fig. 1. (a) Antenna on ground plane and (b) antenna geometry (all dimensions are in $\mathrm{mm}$ ). Dimensions represent an antenna printed on a 1.5 -mm-thick FR4 substrate.

\section{ANTENNA MODEL}

We used the spiral geometry shown in Fig. 1 to design and test our diversity antenna system. This geometry creates a longer current flow path which allows the design and development of a smaller antenna. Meander or Hilbert geometries can also be used. As illustrated in Fig. 1(a), the antenna is operated against a metal ground plane $(110 \mathrm{~mm}$ by $40 \mathrm{~mm})$. The antenna height from the ground plane was kept fixed at $7 \mathrm{~mm}$. An exactly same size and type antenna was placed on the opposite corner of the ground plane. The small gap at the bottom of the "Feed" pin represents where the inner conductor of the coaxial cable is connected. The shorting pin is directly soldered to the ground. Both the feed and shorting pins were made from 1-mm-wide metal strips.

For simplicity of measurement, instead of mounting the antennas on the ground plane in air, they were instead first fabricated on a 1.5-mm-thick FR4 board (not shown in Fig. 1). The other side of the FR4 board did not have a metal ground. 


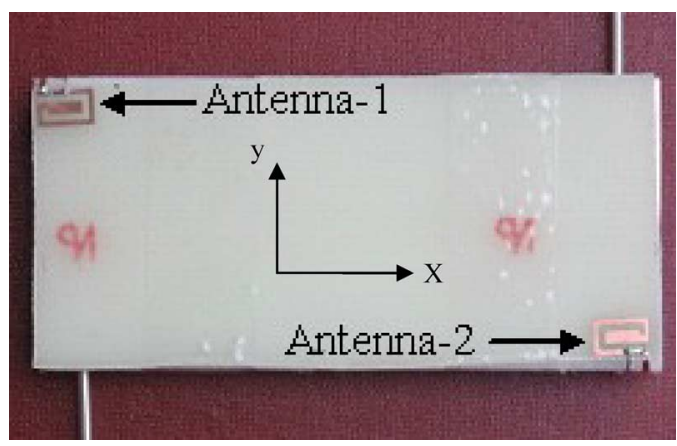

Fig. 2. Photograph of the spiral diversity antenna system.

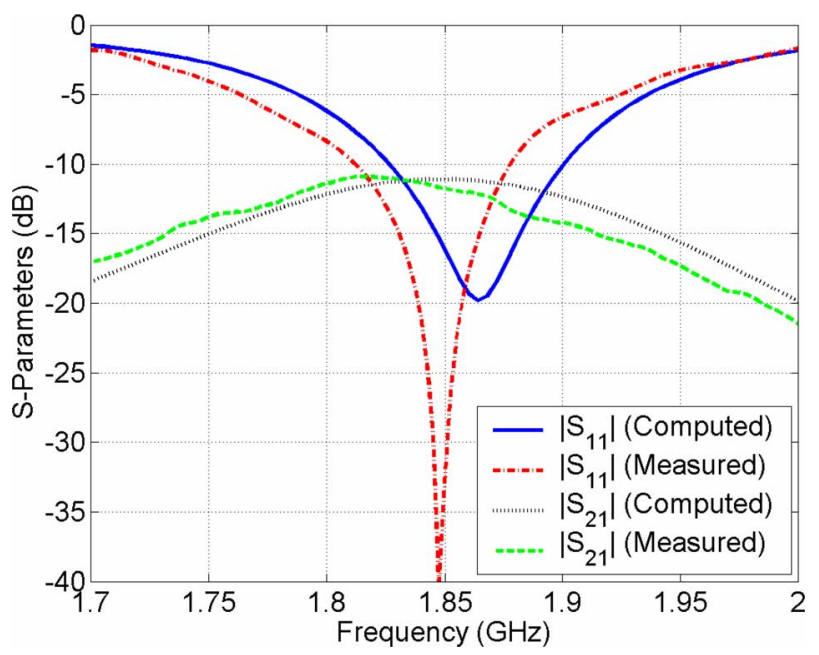

Fig. 3. Computed and measured S-parameters of the proposed diversity antenna scheme.

Then this board containing the two antennas was placed on a 5.5-mm-thick foam. The ground plane was placed underneath the foam. Each antenna was then fed using a coaxial line as shown in the photograph of Fig. 2.

\section{RESULTS}

\section{A. S-Parameters and Radiation Patterns}

Computed (HFSS [8]) and measured S-parameters of the diversity antenna system are shown in Fig. 3. In general, the simulated and measured data show good agreement. The measured center frequency is about $20 \mathrm{MHz}$ lower than the simulated center frequency. Measured bandwidth is $6.9 \%$ within $-6 \mathrm{~dB}$ of $\left|\mathrm{S}_{11}\right|$. Measured and simulated isolation data $\left(\mathrm{S}_{21}\right)$ demonstrate that the isolation between the two antennas is better than $-10 \mathrm{~dB}$, which is good. Note that if the antenna size is larger than the proposed spiral PIFA or that if the antennas are placed much closer to each other or both, then the isolation will degrade. To solve such a problem, one may introduce slits on the ground plane [9] or use engineered structures [10] if the design scenario permits such adjustments.

\section{B. Space Diversity}

In this letter, a switched diversity scheme was considered for which one antenna is excited while the other remains open [6]. The envelope correlation coefficient $\left(\rho_{\mathrm{e}}\right)$ is a measure that is used to determine the efficacy of the diversity system. Radiation pattern data are used to determine the complex correlation coefficient $\rho_{\mathrm{c}}$ [6], [11]. After which, $\rho_{\mathrm{e}}$ is evaluated as $\rho_{\mathrm{e}} \approx\left|\rho_{\mathrm{c}}\right|^{2}$.

In addition to the correlation coefficient, another figure of merit is widely used to assess the quality of a diversity scheme. It is called the mean effective gain (MEG) [11], [12]. Mean effective gain of both the antennas and the ratio of these (MEG1/ MEG2) were calculated. For good diversity the condition is such that $\rho_{\mathrm{e}}<0.5$ and the ratio of MEG1/MEG2 is as close to 1.0 as possible [11]. For the proposed spiral PIFA under the switched diversity scheme, it was computed $\rho_{\mathrm{e}}=0.09$ and MEG1/MEG2 $=0.9979$. By contrast, consider the diversity scheme reported in [5], where $\rho_{\mathrm{e}}$ was found to be less than 0.39 . The significant improvement in the correlation coefficient has been achieved due to the design of a miniature antenna with increased isolation between them.

In Fig. 4 computed realized gain patterns are shown. In the $x y$-plane the diversity antenna scheme clearly complements each other. For instance, at an azimuth angle of $65^{\circ}$, Antenna 1 has peak gain of $-9 \mathrm{dBi}$ while Antenna 2 has peak gain of $-3 \mathrm{dBi}$. Therefore switching from Antenna 1 to 2 would result in a gain improvement by $6 \mathrm{~dB}$. Thus, not surprisingly when one antenna has low gain the other antenna can compensate for it. Similar situations are also observed in the $x z$ - and $y z$-planes. In the $y z$-plane, which is normally the azimuth plane for the phone in its normal vertical upright position, the lowest gain for the diversity antenna scheme is about $-2.5 \mathrm{dBi}$. In comparison the single antenna has its lowest peak gain of $-8.5 \mathrm{dBi}$ in the same $y z$-plane.

\section{Measured Received Power $\left(P_{r}\right)$}

The power received $\left(P_{r}\right)$ by the diversity antenna system was measured in our lab. The measurement was non-line-of-sight and consisted of a resonant omnidirectional monopole antenna (39 $\mathrm{mm}$ long) on a ground plane ( $150 \mathrm{~mm}$ by $150 \mathrm{~mm}$ ) on the transmitter side. The approximate straight line distance between the transmitter and the receiver was $30 \mathrm{ft}$. The schematic of the experimental setup is illustrated in Fig. 5, where NA = network analyzer (Agilent 8719ES), $\mathrm{PA}=$ power amplifier (OPHIR, $0.8-2.0 \mathrm{GHz}, 7 \mathrm{~W}$ ), $\mathrm{TA}=$ transmit antenna, $\mathrm{RA}=$ receive antenna (proposed diversity spiral PIFA), PS = power sensor (Agilent E9326A) and $\mathrm{PM}=$ power meter (Agilent E4417A). Measured $P_{r}$ of the proposed switched diversity PIFA are listed in Table I. Table I clearly demonstrates that if one antenna (either Antenna 1 or Antenna 2) receives poor signal, then the other antenna can take over because it has a higher signal strength, which is also evident from Fig. 4.

\section{Effect of Hand on Antenna Return Loss}

In a realistic scenario, the proposed antenna system will be held by a hand and placed near the head in the talk position. We considered the SAM phantom head [7] and a model of the right hand similar to [13] and performed simulations in XFDTD [14] (see Fig. 6). The frequency dependant tissue equivalent dielectric properties of the SAM phantom were chosen from the IEEE 1528 document [7], while that of the finite-difference time-domain (FDTD) hand model were obtained from [13]. In XFDTD, 


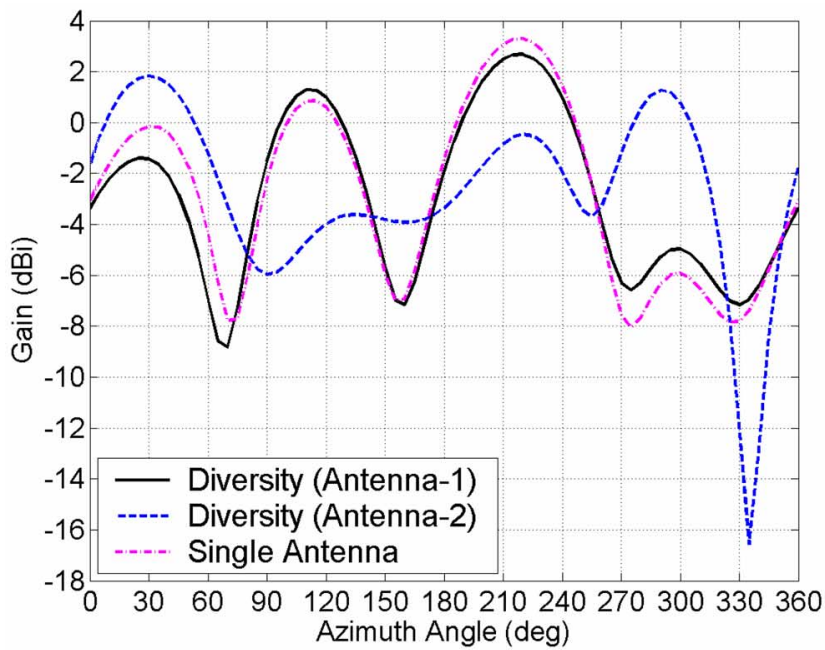

(a)

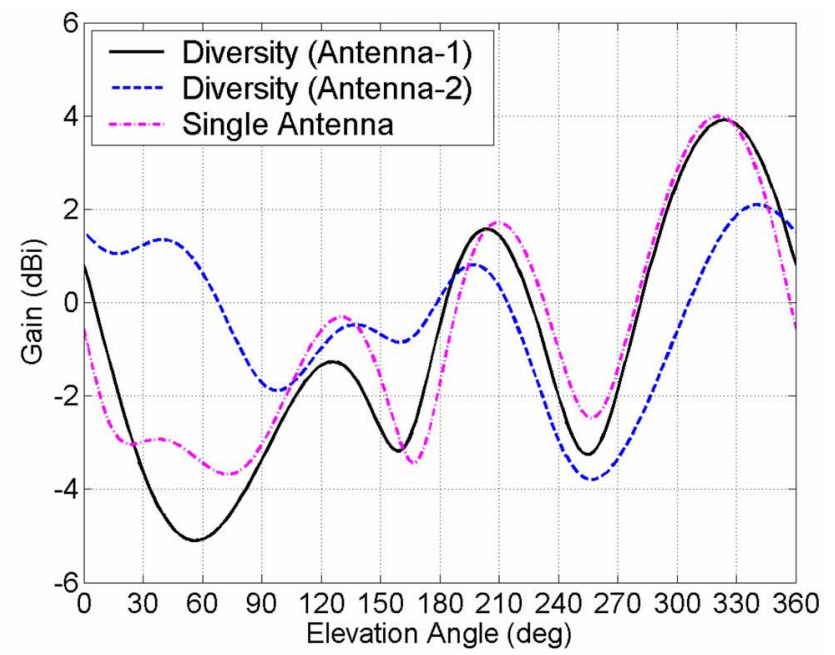

(b)

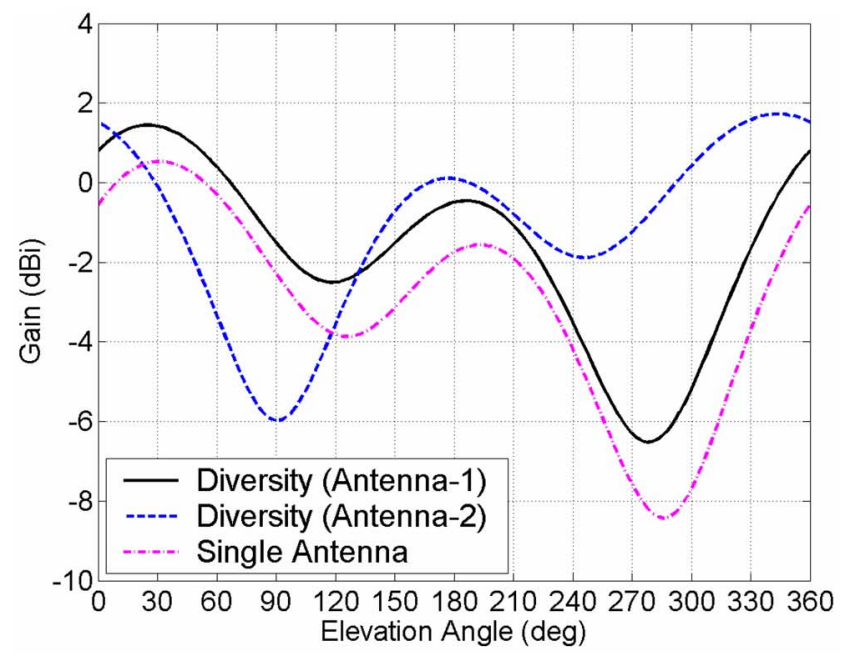

(c)

Fig. 4. Computed antenna gain patterns (a) $x y$-plane, (b) $x z$-plane, and (c) $y z$-plane.

an adaptive mesh of $0.25 \mathrm{~mm}$ was used around the antenna region, while a fixed mesh of $1 \mathrm{~mm}$ was used for all other parts of the model. Liao absorbing boundary condition was used. The

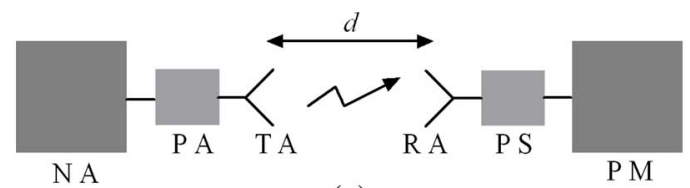

(a)

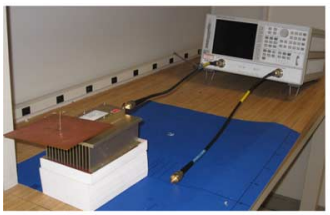

(b)

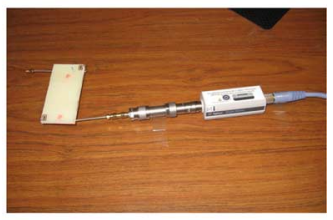

(c)
Fig. 5. (a) Schematic of the received power measurement set-up, (b) transmit antenna system, and (c) receive antenna system.

TABLE I

MEASURED RECEIVED POWER IN THE $x y$-PLANE AT $1860 \mathrm{MHz}$

\begin{tabular}{ccc}
\hline Orientation & \multicolumn{2}{c}{$P_{r}($ Diversity), $\mathrm{dBm}$} \\
\hline $\left.\boldsymbol{\circ}^{\circ}\right)$ & Antenna-1 & Antenna-2 \\
\hline 0 & -22.0 & -14.5 \\
\hline 45 & -21.0 & -13.5 \\
\hline 90 & -19.0 & -23.0 \\
\hline 135 & -10.0 & -21.0 \\
\hline 180 & -17.0 & -18.5 \\
\hline 225 & -12.0 & -20.0 \\
\hline 270 & -19.0 & -17.5 \\
\hline 315 & -21.5 & -12.5 \\
\hline \hline
\end{tabular}

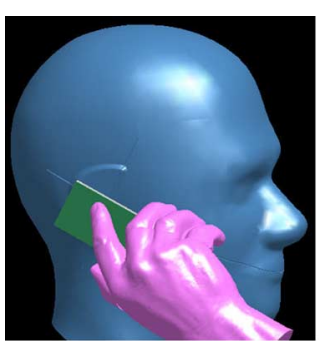

(a)

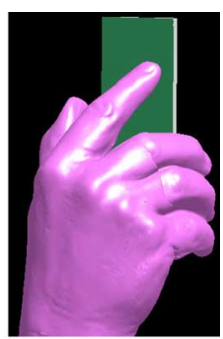

(b)
Fig. 6. Antenna orientation with respect to (a) SAM phantom and right hand and (b) right hand.

shortest distance of the nearest surface of the hand was $7 \mathrm{~mm}$ away from an antenna. The distance of the ground plane was $10 \mathrm{~mm}$ from the nearest surface of the SAM head model.

Computed S-parameters of the proposed antenna system near the SAM phantom held by the right hand are presented in Fig. 7. Comparing Figs. 3 and 7, it is evident that the dielectric materials of the head and the hand have loaded the antenna and detuned it to $1800 \mathrm{MHz}$. The isolation $\left(\left|\mathrm{S}_{21}\right|\right)$ between the two antennas is still better than $10 \mathrm{~dB}$. To bring the antenna's resonant frequency back to $1860 \mathrm{MHz}$, the antenna length was slightly shortened (the $6 \mathrm{~mm}$-long element in Fig. 1(b) was shortened to $5 \mathrm{~mm})$. The return loss $\left(\left|\mathrm{S}_{11}\right|\right)$ of the modified antenna is shown using the dashed line in Fig. 7.

\section{E. Specific Absorption Rate (SAR)}

SAR was computed using XFDTD with reference to $1 \mathrm{~W}$ of power. The phantom scenarios considered were: 1) only head, 2 ) only hand, and 3) both head and hand. The antenna cases were 


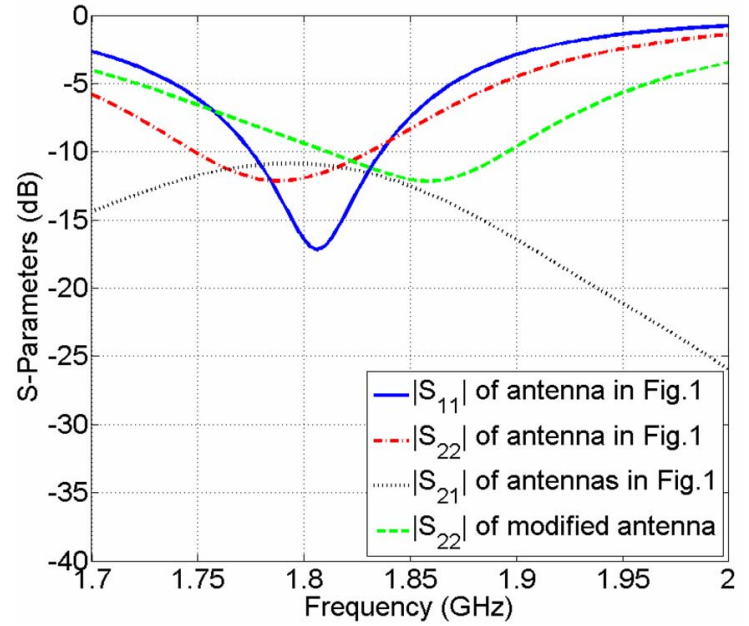

Fig. 7. Computed S-parameters of the proposed diversity antenna scheme held by the right hand near the SAM phantom.

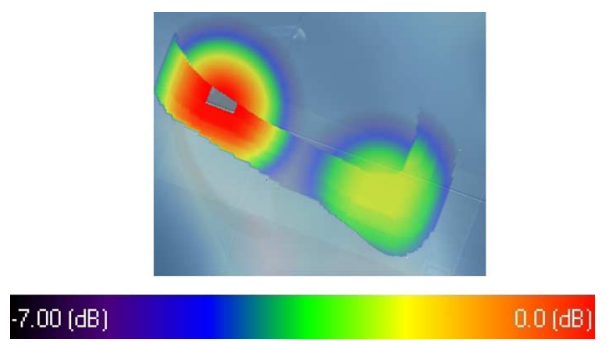

Fig. 8. Peak 1-g average SAR distribution of the diversity antenna system (ground plane $10 \mathrm{~mm}$ from SAM, no hand).

a single antenna, two-element switched diversity antenna, and a two-element antenna system where both antennas were excited. In all cases, when the hand is present, antenna 2 is under the palm of the hand. SAR $(1-\mathrm{g})$ distribution corresponding to the switched diversity scheme is shown in Fig. 8 for the head-only case. It is interesting to notice that for the switched diversity scheme only one antenna is excited, but the results reveal a second "hot-spot" in Fig. 8. Computed SAR data for all the cases are listed in Table II. Clearly the SAR for a single antenna is considerably higher than the SAR for the two-antenna system. The presence of the hand increases the SAR compared to the head-only case for all scenarios.

\section{CONCLUSION}

The radiation and SAR characteristics of a miniature spiral PIFA diversity antenna system are studied for $1850-\mathrm{MHz}$ mobile phone application. The isolation between the diversity antennas in free-space as well as near head and hand are better than $-10 \mathrm{~dB}$. The envelope correlation coefficient is significantly smaller than $0.5\left(\rho_{\mathrm{e}}=0.09\right)$, which clearly indicates that the proposed antenna system holds excellent promise for switched diversity application in a mobile device. Furthermore,
TABLE II

COMPUTED SAR OF PROPOSED SPIRAL PIFA

\begin{tabular}{cccc}
\hline \hline & $\begin{array}{c}\text { Peak Gain } \\
(\mathrm{dBi})\end{array}$ & $\begin{array}{c}S A R \\
(W / K G) \\
\text { Number of }\end{array}$ & $\begin{array}{c}S A R \\
(W / K G) \\
\text { Antennas, Position }\end{array}$ \\
\hline One, Head & 4.64 & 5.32 & 3.14 \\
\hline One, Hand & N/A & 8.67 & 4.37 \\
\hline One, Head Hand & -0.84 & 7.47 & 3.84 \\
\hline Two (Diversity), Head & 4.64 & 4.69 & 2.74 \\
\hline Two (Diversity), Hand & N/A & 6.94 & 3.86 \\
\hline Two (Diversity), Head Hand & -0.51 & 5.43 & 3.37 \\
\hline Two (both excited), Head & 3.96 & 4.25 & 2.5 \\
\hline Two (both excited), Hand & N/A & 5.51 & 3.47 \\
\hline Two (both excited), Head Hand & -0.25 & 4.73 & 3.45 \\
\hline \hline
\end{tabular}

computed SAR data against a SAM phantom indicate that the switched diversity antenna system induces lower SAR than a single antenna for both the $1-\mathrm{g}$ and $10-\mathrm{g}$ average cases.

\section{ACKNOWLEDGMENT}

The authors would like to express their sincere thanks to Motorola, Inc.

\section{REFERENCES}

[1] R. G. Vaughan and J. B. Andersen, "Antenna diversity in mobile communications," IEEE Trans. Veh. Technol., vol. VT-36, no. 4, pp. 149-172, Nov. 1987.

[2] K. Fujimoto, Mobile Antenna Systems Handbook, 2nd ed. Norwood, MA: Artech House, Feb. 2001.

[3] M. G. Douglas, M. Okoniewski, and M. A. Stuchly, "A planar diversity antenna for handheld PCS device," IEEE Trans. Veh. Technol., vol. 47, no. 3, pp. 747-754, Aug. 1998.

[4] C. B. Dietrich, K. Dietze, J. R. Nealy, and W. L. Stutzman, "Spatial, polarization, and pattern diversity for wireless handheld terminals," IEEE Trans. Antennas Propag., vol. 49, no. 9, pp. 1271-1281, Sep. 2001.

[5] K.-C. Chim, K. C. L. Chan, and R. D. Murch, "Investigating the impact of smart antennas on SAR," IEEE Trans. Antennas Propag., vol. 52, no. 5, pp. 1370-1374, May 2004.

[6] M. Z. Azad and M. Ali, "A new class of miniature embedded inverted-F antennas (IFAs) for $2.4 \mathrm{GHz}$ WLAN application," IEEE Trans. Antennas Propag., vol. 54, no. 9, pp. 2585-2592, Sep. 2006.

[7] IEEE Recommended Practice for Determining the Peak Spatial-Average Specific Absorption Rate (SAR) in the Human Head From Wireless Communication Devices: Measurement Techniques, IEEE Std 1528-2003, Piscataway, NJ, USA.

[8] Ansoft HFSS. Ansoft Corporation [Online]. Available: http://www.ansoft.com/products/hf/hfss

[9] M. F. Abedin and M. Ali, "Modifying the ground plane and its effect on planar inverted-F antennas (PIFAs) for mobile phone handsets," IEEE Antennas Wireless Propag. Lett., vol. 2, pp. 226-229, 2003.

[10] M. F. Abedin and M. Ali, "Effects of a smaller unit cell planar EBG structure on the mutual coupling of a printed dipole array," IEEE Antennas Wireless Propag. Lett., vol. 4, pp. 274-276, 2005.

[11] S. C. K. Ko and R. D. Murch, "Compact integrated diversity antennas for wireless communications," IEEE Trans. Antennas Propag., vol. 49, no. 6, pp. 954-960, Jun. 2001.

[12] M. Karaboikis, C. Soras, G. Tsachtsiris, and V. Makios, "Compact dual-printed inverted-F antenna diversity systems for portable wireless devices," IEEE Antennas Wireless Propag. Lett., vol. 3, pp. 9-14, 2004.

[13] C. Gabriel, "Tissue equivalent material for hand phantoms," Phys. Med. Biol., vol. 52, pp. 4205-4210, 2007.

[14] XFDTD. Remcom, State College, PA [Online]. Available: http://www. remcom.com/xfdtd6 